\title{
(6) OPEN ACCESS \\ Therapeutic guidelines for prescribing antibiotics in neonates should be evidence-based: a French national survey
}

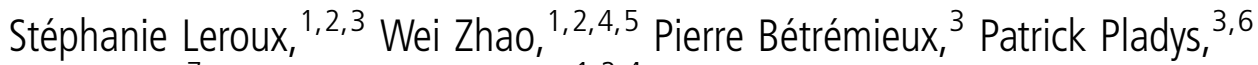 \\ Elie Saliba, ${ }^{7}$ Evelyne Jacqz-Aigrain, ${ }^{1,2,4}$ on behalf of the French Society of \\ Neonatology
}

For numbered affiliations see end of article.

\section{Correspondence to}

Dr Evelyne Jacqz-Aigrain, Department of Pediatric

Pharmacology and

Pharmacogenetics, Clinical Investigation Center CIC1426, INSERM, Hôpital Robert Debré, 48 Boulevard Sérurier, 75935

Paris Cedex 19, France;

evelyne.jacqz-aigrain@rdb. aphp.fr

Received 1 June 2014 Revised 12 September 2014 Accepted 21 September 2014 Published Online First 27 February 2015

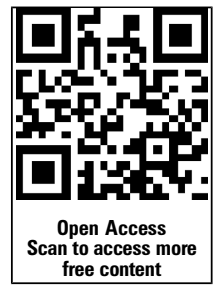

\section{SLinked}

http://dx.doi.org/10.1136/ archdischild-2014-307762

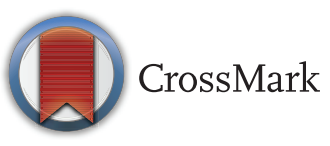

To cite: Leroux $S$, Zhao W, Bétrémieux $\mathrm{P}$, et al. Arch Dis Child 2015;100:394-398.

\section{ABSTRACT}

Objective This survey aims to describe and analyse the dosage regimens of antibiotics in French neonatal intensive care units (NICUs).

Methods Senior doctors from 56 French NICUs were contacted by telephone and/or email to provide their local guidelines for antibiotic therapy.

Results 44 (79\%) NICUs agreed to participate in this survey. In total, 444 dosage regimens were identified in French NICUs for 41 antibiotics. The number of different dosage regimens varied from 1 to 32 per drug (mean 9, SD 7.8). $37 \%$ of intravenous dosage regimens used a unique $\mathrm{mg} / \mathrm{kg}$ dose from preterm to full-term neonates. Doses and/or dosing intervals varied significantly for 12 antibiotics (amikacin, gentamicin, netilmicin, tobramycin, vancomycin administered as continuous infusion, ceftazidime, cloxacillin, oxacillin, penicillin $\mathrm{G}$, imipenem/ cilastatin, clindamycin and metronidazole). Among these antibiotics, 6 were used in more than $70 \%$ of local guidelines and had significant variations in (1) maintenance daily doses for amikacin, imipenem/ cilastatin, ceftazidime and metronidazole; (2) loading doses for continuous infusion of vancomycin; and (3) dosing intervals for gentamicin and amikacin. Conclusions A considerable inter-centre variability of dosage regimens of antibiotics exists in French NICUs. Developmental pharmacokinetic-pharmacodynamic studies are essential for the evaluation of antibiotics in order to establish evidence-based dosage regimens for effective and safe administration in neonates.

\section{INTRODUCTION}

Neonatal bacterial sepsis, classified as early or late onset, is a major cause of mortality and morbidity, particularly for premature neonates. ${ }^{1}{ }^{2}$ Suspected infections are quite frequent in premature newborns and empirical antibiotic therapy is an emergency. If treatment is delayed or ineffective, neonatal sepsis can be rapidly fatal, making optimal use of antibiotics essential.

Previous work demonstrated a considerable variation of dosage regimens of vancomycin and gentamicin among UK neonatal intensive care units (NICUs). ${ }^{3}$ This implies that either toxic or subtherapeutic treatment courses may exist in neonatal clinical care, which obviously impacts clinical outcomes, especially for drug with narrow therapeutic index, such as aminoglycosides and vancomycin. We speculated that the variation in the dosage

\section{What is already known on this topic?}

Most antibiotics are used off-label in neonates.

- Local practice is variable to manage antimicrobial therapy in neonates.

- Previous work demonstrated a considerable variation of dosage regimens of vancomycin and gentamicin among UK neonatal intensive care units.

\section{What this study adds?}

A considerable inter-centre variability of dosage regimens of antibiotics exists in French neonatal intensive care units.

- Evidence-based dosage regimens of antibiotics should be validated for neonatal treatment on the basis of developmental pharmacokineticspharmacodynamics.

regimens is a common problem for antibiotic therapy in neonates because of limited number of high quality pharmacokinetic-pharmacodynamic studies. We surveyed local guidelines for antibiotic therapy in all French NICUs to evaluate the current local dosage recommendations.

\section{METHODS}

\section{Data collection}

A total of 56 level 3 NICUs were identified from the directory of French paediatric intensive care network (Groupe Francophone de Reanimation et Urgences Pédiatriques): 54 metropolitan and 2 overseas. A senior doctor from each NICU was contacted by phone and/or email between May and June 2013 to participate in this survey.

\section{Therapeutic guidelines and data extraction}

All local therapeutic guidelines typically included various antibiotics, each of them with different dosage regimen defined by a dose and a dosing interval, based primarily on patients' variables such as age, weight and/or renal function. The following data were extracted for each antibiotic in all guidelines: (1) drug name; (2) lower and upper bound 
values for the daily doses $(\mathrm{mg} / \mathrm{kg} /$ day) and dosing intervals $(\mathrm{h})$; and (3) variables for dosage individualisation, when used (i.e., age or weight). Exclusion criteria included: (1) dosage recommendations for infants with a postmenstrual age over 44 weeks 4 or (2) therapeutic guidelines for meningitis.

\section{Data analysis}

The number of antibiotics in each local guideline, the number of dosage regimens and the distribution (minimum, median, maximum) of the lower bound and upper bound of daily dose and dosing interval in each local guideline were described for each antibiotic. Median of daily doses and dosing intervals for all the guidelines were calculated for each antibiotic. Inter-centre variability was assessed by comparing the medians of the daily dose and dosing interval among NICUs using nonparametric statistical test of Kruskal-Wallis ( $\mathrm{n}>2$ medians) or Mann-Whitney-Wilcoxon ( $\mathrm{n}=2$ medians). Statistical analyses were conducted using R software (V.3.0). A value of $\mathrm{p}<0.05$ was considered statistically significant.

\section{RESULTS}

All 56 French level 3 NICUs were contacted: 3 declared no local antibiotic guidelines and 9 declined participation. Thus, $44(79 \%)$ agreed to participate.

Each local guideline included a mean of 16 antibiotics (range 5-24). A total of 41 antibiotics were identified, including 19 beta-lactams, 4 aminoglycosides, 2 glycopeptides, 3 fluoroquinolones, 6 macrolides, 2 imidazoles, 1 sulfonamide and 4 other antibacterial agents. They are administered intravenously $(n=31)$, orally $(n=3)$ or both $(n=7)$. Intravenous administration was either intermittent $(n=37)$ or both intermittent and continuous $(n=1)$, with a loading dose strategy in 4 cases (metronidazole, ornidazole, teicoplanin, vancomycin). The different sources from which the local guidelines were developed are illustrated in figure 1.

Inter-centre variability in daily dose and dosing intervals

Antibiotics with significant inter-centre variability in median daily doses and dosing intervals are presented in table 1 .

\section{Daily dose}

The daily doses were significantly different among NICUs for 9 antibiotics, administrated intravenously.

Maintenance daily doses were significantly different among NICUs for 8 antibiotics (amikacin, penicillin G, imipenem/cilastatin, netilmicin, cloxacillin, oxacilline, metronidazole, ceftazidime); 4 of them (amikacin, imipenem/cilastatin, metronidazole, ceftazidime) were included in more than $70 \%$ of local guidelines and their median daily doses varied from 2 to 5 times. Table 1 compared their doses in local guidelines with doses recommended by Neofax and Redbook.

Loading doses were significantly different for continuous infusion vancomycin $(p<0.001)$, which was included in $78.4 \%$ of local guidelines. The loading dose varied 3 times $(7-20 \mathrm{mg} / \mathrm{kg})$.

\section{Dosing intervals}

The dosing intervals were significantly different for 5 antibiotics: gentamicin $(p<0.001)$, amikacin $(p<0.001)$, netilmicin $(\mathrm{p}<0.001)$, tobramycin $(\mathrm{p}<0.001)$ and clindamycin $(\mathrm{p}=0.023)$. Gentamicin and amikacin were included in more than $70 \%$ of local guidelines and median dosing intervals varied 3.5 times (12-42 h) (table 1).

\section{Dosage individualisation}

A total of 444 dosage regimens (407 intravenous and 37 oral) were used in French NICUs for 41 antibiotics. The number of

Figure 1 Sources for local guidelines.

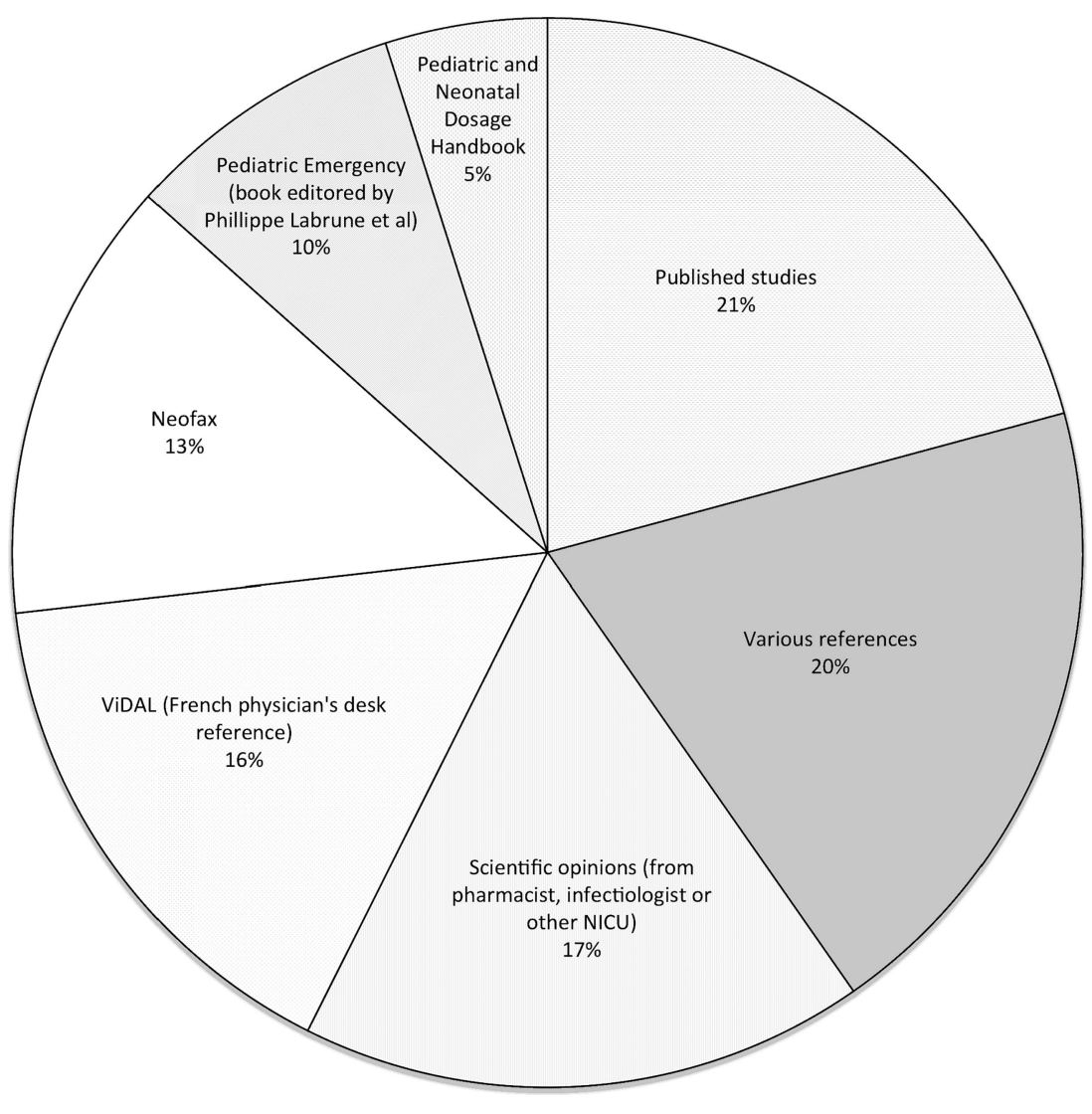


Table 1 The daily doses and dosing intervals of antibiotics with significant inter-centre variability: comparison with Neofax and RedBook

\begin{tabular}{|c|c|c|c|c|c|c|}
\hline \multirow[b]{2}{*}{ Antibiotic } & \multicolumn{3}{|c|}{ Minimal daily doses } & \multicolumn{3}{|c|}{ Maximal daily doses } \\
\hline & $\begin{array}{l}\text { Survey results } \\
\text { (mg/kg/day) } \\
\text { (Min-max) }\end{array}$ & $\begin{array}{l}\text { Neofax } \\
\text { (mg/kg/day) }\end{array}$ & $\begin{array}{l}\text { RedBook } \\
\text { (mg/kg/day) }\end{array}$ & $\begin{array}{l}\text { Survey results } \\
\text { (mg/kg/day) } \\
\text { (Min-max) }\end{array}$ & $\begin{array}{l}\text { Neofax } \\
\text { (mg/kg/day) }\end{array}$ & $\begin{array}{l}\text { RedBook } \\
\text { (mg/kg/day) }\end{array}$ \\
\hline Amikacin & $4.0-15.0$ & 9.0 & 7.5 & $13.3-27.5$ & 15.0 & 30.0 \\
\hline Penicillin G & $50.0-200.0$ & 30.0 & 30.0 & $150.0-300.0$ & 90.0 & 90.0 \\
\hline Imipenem/cilastatin & $20.0-75.0$ & 40.0 & 40.0 & $40.0-100.0$ & 50.0 & 75.0 \\
\hline Netilmicin & $2.0-6.0$ & 2.5 & NA & $4.0-7.5$ & 4.0 & NA \\
\hline Cloxacillin & $50.0-180.0$ & NA & NA & $75.0-180.0$ & NA & NA \\
\hline Oxacillin & $25.0-180.0$ & 50.0 & 50.0 & $75.0-300.0$ & 75.0 & 100.0 \\
\hline Metronidazole & $3.75-30.0$ & 3.75 & 3.75 & $15.0-40.0$ & 15.0 & 30.0 \\
\hline \multirow[t]{3}{*}{ Ceftazidime } & $25.0-200.0$ & 60.0 & 100.0 & $50.0-200.0$ & 90.0 & 150.0 \\
\hline & \multicolumn{3}{|c|}{ Minimal dosing intervals } & \multicolumn{3}{|c|}{ Maximal dosing intervals } \\
\hline & $\begin{array}{l}\text { Survey results } \\
\text { (h) } \\
\text { (Min-max) }\end{array}$ & $\begin{array}{l}\text { Neofax } \\
\text { (h) }\end{array}$ & $\begin{array}{l}\text { RedBook } \\
\text { (h) }\end{array}$ & $\begin{array}{l}\text { Survey results } \\
\text { (h) } \\
\text { (Min-max) }\end{array}$ & $\begin{array}{l}\text { Neofax } \\
\text { (h) }\end{array}$ & $\begin{array}{l}\text { RedBook } \\
\text { (h) }\end{array}$ \\
\hline Clindamycin & $6-8$ & 8 & 6 & $6-12$ & 12 & 12 \\
\hline Amikacin & $8-24$ & 24 & 12 & $18-60$ & 48 & 48 \\
\hline Netilmicin & $8-24$ & 24 & NA & $18-48$ & 48 & NA \\
\hline Gentamicin & $8-24$ & 24 & 12 & $12-48$ & 48 & 48 \\
\hline Tobramycin & $8-48$ & 24 & 12 & $24-72$ & 48 & 48 \\
\hline
\end{tabular}

different dosage regimens per antibiotic ranged from 1 to 32 . In all, $37 \%$ of intravenous and $87 \%$ of oral dosage regimens used a unique $\mathrm{mg} / \mathrm{kg}$ dose, without taking into account any patients' characteristics. The most used covariate of dosage individualisation was age, which appeared in $88 \%$ of individualised dosage regimens.

\section{DISCUSSION}

This study analysed the local guidelines used to prescribe antibiotics in the French NICUS and included 44 guidelines with a total of 41 antibiotics. Our data show considerable inter-centre variability as the number of antibiotics per local guideline varied from 5 to 24 and the number of dosage regimens from 1 to 32 per drug, with important differences in daily doses, dosing intervals and covariates used for dosage individualisation. These data highlighted the urgent need to optimise antibiotic prescriptions in neonates and developing evidence-based therapeutic consensus from already available data.

Antibiotics are extensively prescribed in neonates as infections are frequent and associated with a high risk of morbidity and mortality. ${ }^{5}$ However, few antibiotics have been evaluated in order to obtain a marketing authorisation for neonatal use and most of them are used off-label. ${ }^{78}$

As microbiologically evaluated infection is rare in neonates, ${ }^{9}$ treatment has to be started as early as possible and merely upon clinical suspicion. The initial choice of antibiotic therapy will depend on the clinical context and local bacterial epidemiology, while dosing will be ultimately determined by the area under the inhibitory curve AUIC (i.e., the $\mathrm{AUC}_{24}$ to MIC ratio of the antibiotic area under the concentration-time curve to the organism's minimum inhibitory concentration). ${ }^{10}$ To determine such ratio, MIC is based on sensitivity and resistance breakpoints of microorganisms provided by 'The European Committee on Antimicrobial Susceptibility Testing-EUCAST' or by the 'Clinical Laboratory Standards Institute'11-13 while AUC is patient dependant. Therefore, appropriate neonatal dosing needs to integrate the rapid developmental changes of the neonatal period, as reflected by covariates influencing drug disposition. ${ }^{14}$ Depending on the drug, these covariates are markers of size and maturation and may include gestational, postnatal, postmenstrual age, creatine concentration liver function tests and so on. Additional variables may be tested: disease, associated drugs, cardiovascular and ventilatory support.

Accordingly, regulatory guidelines ${ }^{15-17}$ recommend pharmacokinetic modelling and simulation approaches to establish neonatal dosage recommendation of antibiotics, underlying the importance of well designed pharmacokinetic studies.

However, evidence-based dosing regimens to support optimal prescriptions are lacking for almost all antibiotics in neonates, as illustrated by the two extreme examples of amikacin and metronidazole.

(1) For amikacin, 19 different neonatal dosing regimens are proposed in the literature ${ }^{18-32}$ and 31 were identified in the present study. None of them were clinically validated resulting in the lack of consensus on the optimal dosage regimen to be used in neonates. A consensus on neonatal dosing can only be evidence-based and requires a validated pharmacokinetic model (with both internal and external validation) but also clinical evaluation of the proposed regimen by a prospective efficacy and safety study. ${ }^{33}$ As pharmacokinetic studies in neonates usually have a limited number of patients included in many centres, study-related factors (such as characteristics of the neonates included, analytical methods to measure biological covariates or drug concentrations.) may have an important impact when extrapolating the published results to different clinical settings. ${ }^{34}$ In such cases, population pharmacokinetic meta-analysis might ensure thorough understanding of study-related pharmacokinetic differences in drug disposition, a prerequisite for clinical evaluation of efficacy and safety.

(2) For metronidazole, only 2 population pharmacokinetic studies with a limited number of neonates $(n=32)$ have been published, ${ }^{35} 36$ even though the drug has been used for many 
years for treating complicated abdominal infections in neonates. Additional data are obviously required as treated patients are highly variable from extremely low birth weight to term neonates.

The French inter-NICU variability reported in this survey almost certainly reflects more common situations encountered in European countries or at the international level. Indeed, such heterogeneity in clinical practice is in agreement with previous data evaluating the dosage recommendations of vancomycin and gentamicin ${ }^{3}$ or ciprofloxacin. ${ }^{37}$ The National Institute of Health and Care Excellence guidance recommends a unique gentamicin starting dose of $5 \mathrm{mg} / \mathrm{kg}$ every $36 \mathrm{~h}$ for early onset neonatal infection treatment; ${ }^{38}$ however, the current clinical practice is variable for gentamicin therapy. In UK survey, 24 different combinations of dose were revealed and the dosing interval varied markedly from 12 to $48 \mathrm{~h}$. In a French survey, we found 25 different combinations of doses and the dosing interval varied from 8 to 48 h. For vancomycin, clinical practice is even more variable in France, as both of continuous infusion and intermittent infusion were routinely used. Our results are also consistent with the previous findings by Porta $e t a l^{39}$ who reported wide variation between four children's hospitals in the type and dose of antibiotic used in paediatrics based on daily prescription data.

We further compared the doses in local guidelines with dosages recommended by Neofax and Redbook, ${ }^{40} 41$ as they are frequently used reference books by neonatologists. Inconsistencies were highlighted, e.g. for ceftazidime, Neofax recommends $30 \mathrm{mg} / \mathrm{kg}$ per dose every 8 or $12 \mathrm{~h}$ according to postmenstrual age and postnatal age, while RedBook recommends $50 \mathrm{mg} / \mathrm{kg}$ per dose every 8 or $12 \mathrm{~h}$ according to body weight and postnatal age. Reaching a consensus on antibiotic therapy in neonates is urgently required, but will need close collaboration between paediatric pharmacologists and neonatologists.

Such variability in local guidelines, along with the paucity and poor quality of randomised controlled trials, highlights the difficulties in conducting studies assessing the effects of antibiotics in neonates, ${ }^{42} 43$ despite regulatory initiatives that encourage drug studies in neonatology. ${ }^{44}$ Several factors may explain this situation: (1) signs of neonatal sepsis (either early or late onset sepsis) are unspecific and antibiotic treatment has to be started as early as possible and merely upon clinical suspicion; ${ }^{9}$ (2) the empirical treatment varies between units, as it depends on local epidemiology and clinical context; (3) antibiotics with proven efficacy and safety in older paediatric patients or even adults frequently enter neonatal care because clinicians perceive them to have a more adapted spectrum of activity and/or better risks to benefit ratio than the currently used antibiotics; and (4) in such emergency situations, and whatever the study design (pharmacokinetics and safety or randomised controlled trial for efficacy), informed consent is difficult to obtain. ${ }^{45} 46$

In conclusion, this survey analysed the multiple dosage regimens to be followed to prescribe antibiotics in the French NICUs. A wide inter-centre variability was evidenced in terms of daily doses, dosing intervals and covariates used for dosage individualisation. Obviously, evidence-based dosage regimens of antibiotics should be validated for neonatal treatment on the basis of developmental pharmacokinetics-pharmacodynamics.

\section{Author affiliations}

1 Department of Paediatric Pharmacology and Pharmacogenetics, Hôpital Robert Debré, APHP, Paris, France

${ }^{2}$ EA7323, Université Paris Diderot-Université Paris Descartes, Paris, France
${ }^{3}$ Division of Neonatology, Department of Child and Adolescent Medicine, CHU de Rennes, Rennes, France

${ }^{4}$ Clinical Investigation Center CIC1426, INSERM, Paris, France

${ }^{5}$ Department of Clinical Pharmacy, School of Pharmaceutical Sciences, Shandong University, Jinan, China

${ }^{6}$ INSERM U1099, Institut des Neurosciences Cliniques de Rennes, Rennes, France

${ }^{7}$ Paediatric and Neonatal Intensive Care Unit, CHRU Tours, Tours, France

Acknowledgements We acknowledge all neonatologists from paediatric and neonatal intensive care network (listed in alphabetic order) who participated in this survey (CH: centre hospitalier): Amiens CHU (G. Kongolo), Angers CHU Hôtel Dieu (S. Le bouedec, B. Leboucher), Arras CH (B. Theret, L. Desnoulez), Bayonne CH de la Côte Basque (P. Jouvencel), Bicêtre Hôpital Bicètre (D. Devictor, L. Chevret), Brest CHRU Morvan Brest (A. Garenne, JM. Roue), Caen, Hôpital Côte de Nacre (B. Guillois, A. Ceneric), Calais CH (MJ. Thieuleux, L. Egreteau), Clamart Hôpital Antoine Béclère (O. Romain), Chambery CH (M. Deiber), Cherbourg CH public du Cotentin (S. Saumureau), Clermont-Ferrand Hôpital Estaing (B. Bœuf, V. Poirier), Creteil-CH Intercommunal (C. Danan, X. Durrmeyer), Grenoble CHU Hôpital Couple Enfant (T. Debillon, L. Marcus, F. Audeoud), Lens CH Docteur Schaffner (C. Morisot, S. Klosowski), Lille Hôpital Jeanne de Flandre (L. Storme, A. Fily), Lyon Hôpital Femme Mère Enfant (O. Claris, F. Plaisant), Lyon Hôpital Croix Rousse (JC. Picaud, I. Jordan), Marseille Hôpital Nord (U. Simeoni, S. Hassid), Marseille Hôpital de la Conception (U. Simeoni, I. Ligi), Montpellier hôpital Arnaud de Villeneuve

(G. Cambonie, R. Mesnage), Montreuil Hôpital André Grégoire (P. Daoud) Mulhouse-Hôpital Hasenrain (J. Nakhleh), Nantes Hôpital Mère-Enfant (JC. Rozé), Nice Hôpital Archet 2 (C. Dageville), Nimes CHU Caremeau (JB. Mariette), Noumea Hôpital Magenta (L. Tauzin), Paris Hôpital Cochin (PH. Jarreau), Paris Hôpital Necker Enfants-Malades (P. Hubert, M. Nicloux), Paris Hôpital Robert Debré (O. Baud, V Biran); Paris Hôpital Trousseau (D. Mitanchez, F. Kieffer), Perpignan Hôpital Saint Jean (P. Thevenot, R. Mesnage), Poissy CH Intercommunal (P. Boileau, G. Ciarlo), Pontoise Hôpital René Dubos (P. Boize), Reims, Hôpital Maison Blanche (P. Morville, A. David), Rouen Hôpital Charles Nicolle (S. Marret), Rennes Hôpital sud Anne de Bretagne (P. Pladys, P. Betremieux), Saint Brieux Hôpital Yves Le Foll (E. Boutaric), Saint Denis La Reunion CHU Felix Guyon (S. Samperiz, D. Ramful), Strasbourg Hôpital Hautepierre (D. Astruc, L. Palpacuer), Tours Hôpital Clocheville (E. Saliba, A. Bouissou), Troyes CH (I. Arnault), Valenciennes CH (F. Lapeyre, M. Hassan), Vannes CH Bretagne Atlantique (H. Journel, H. Bourdial).

Collaborators Societé Française de Neonatologie (http://sdp.perinat-france.org/SFN).

Contributors SL, ZW and EJ-A defined the study. SL contacted the NICUs with the participation of PB, PP and ES. SL, ZW and EJ-A planned the analysis. SL performed the analysis and wrote the first draft of the manuscript. WZ and EJ-A reviewed the manuscript; the last version was validated by all authors.

Funding This work was supported by "Treat Infections in NeoNates network" (TINN1 and TINN2, EU-funded FP7 projects, Grant Agreement numbers no 223614 TINN1; no 260908 TINN2) and Global Research in Paediatrics-Network of Excellence (GRIP, EU-funded FP7 project, Grant Agreement number 261060).

\section{Competing interests None.}

Provenance and peer review Not commissioned; externally peer reviewed.

Open Access This is an Open Access article distributed in accordance with the Creative Commons Attribution Non Commercial (CC BY-NC 4.0) license, which permits others to distribute, remix, adapt, build upon this work non-commercially, and license their derivative works on different terms, provided the original work is properly cited and the use is non-commercial. See: http://creativecommons.org/ licenses/by-nc/4.0/

\section{REFERENCES}

1 Marchant EA, Boyce GK, Sadarangani M, et al. Neonatal sepsis due to coagulase-negative staphylococci. Clin Dev Immunol 2013;2013:586076.

2 Manzoni P, Rizzollo S, Decembrino L, et al. Recent advances in prevention of sepsis in the premature neonates in NICU. Early Hum Dev 2011;87:S31-3.

3 Kadambari S, Heath PT, Sharland M, et al. Variation in gentamicin and vancomycin dosage and monitoring in UK neonatal units. J Antimicrob Chemother 2011;66:2647-50.

4 Engle WA. Age terminology during the perinatal period. Pediatrics 2004;114:1362-4.

5 Clark RH, Bloom BT, Spitzer AR, et al. Reported medication use in the neonatal intensive care unit: data from a large national data set. Pediatrics 2006;117:1979-87.

6 Zingg W, Pfister R, Posfay-Barbe KM, et al. Secular trends in antibiotic use among neonates: 2001-2008. Pediatr Infect Dis J 2011;30:365-70.

7 Zingg W, Posfay-Barbe KM. Antibiotic use in children-off-label use. Curr Drug Targets 2012;13:885-92

8 Neubert A, Lukas K, Leis T, et al. Drug utilisation on a preterm and neonatal intensive care unit in Germany: a prospective, cohort-based analysis. Eur J Clin Pharmacol 2010;66:87-95. 
9 Edmond K, Zaidi A. New approaches to preventing, diagnosing, and treating neonatal sepsis. PLoS Med 2010;7:e1000213.

10 Lutsar I, Metsvaht T. Understanding pharmacokinetics pharmacodynamics in managing neonatal sepsis. Curr Opin Infect Dis 2010;23:201-7.

11 http://www.eucast.org

12 http://www.clsi.org

13 Asín E, Isla A, Canut A, et al. Comparison of antimicrobial pharmacokinetic/ pharmacodynamic breakpoints with EUCAST and CLSI clinical breakpoints for Gram-positive bacteria. Int J Antimicrob Agents 2012;40:313-22.

14 Smits A, Annaert P, Allegaert K. Drug disposition and clinical practice in neonates: cross talk between developmental physiology and pharmacology. Int J Pharm 2013:16:8-13.

15 Guidance for industry: exposure-response relationships—study design, data analysis, and regulatory applications. http://www.fda.gov/downloads/Drugs

16 European Medicines Agency. Points to consider on pharmacokinetics and pharmacodynamics in the development of antibacterial medicinal products. Ref. CPMP/EWP/2655/99). http://www.ema.europa.eu

17 European Medicines Agency. Note for guidance on evaluation of medicinal products indicated for treatment of bacterial infections (CPMP/EWP/558/95 rev 1). http://www.ema.europa.eu

18 Setiabudy R, Suwento R, Rundjan L, et al. Lack of a relationship between the serum concentration of aminoglycosides and ototoxicity in neonates. Int J Clin Pharmacol Ther 2013;51:401-6.

19 De Cock RFW, Allegaert K, Schreuder MF, et al. Maturation of the glomerular filtration rate in neonates, as reflected by amikacin clearance. Clin Pharmacokinet 2012:51:105-17.

20 Abdel-Hady E, El Hamamsy M, Hedaya M, et al. The efficacy and toxicity of two dosing-regimens of amikacin in neonates with sepsis. J Clin Pharm Ther 2011;36:45-52.

21 Schreuder MF, Wilhelm AJ, Bökenkamp A, et al. Impact of gestational age and birth weight on amikacin clearance on day 1 of life. Clin J Am Soc Nephrol 2009:4:1774-8.

22 Siddiqi A, Khan DA, Khan FA, et al. Therapeutic drug monitoring of amikacin in preterm and term infants. Singapore Med J 2009;50:486-9.

23 Sherwin CMT, Svahn S, Van der Linden A, et al. Individualised dosing of amikacin in neonates: a pharmacokinetic/pharmacodynamic analysis. Eur J Clin Pharmacol 2009:65:705-13.

24 Allegaert K, Anderson BJ, van den Anker JN, et al. Renal drug clearance in preterm neonates: relation to prenatal growth. Ther Drug Monit 2007;29:284-91.

25 Allegaert K, Cossey V, Debeer A, et al. The impact of ibuprofen on renal clearance in preterm infants is independent of the gestational age. Pediatr Nephrol 2005;20:740-3.

26 Tréluyer JM, Merlé Y, Tonnelier $\mathrm{S}$, et al. Nonparametric population pharmacokinetic analysis of amikacin in neonates, infants, and children. Antimicrob Agents Chemother 2002;46:1381-7.

27 Labaune JM, Bleyzac N, Maire P, et al. Once-a-day individualized amikacin dosing for suspected infection at birth based on population pharmacokinetic models. Biol Neonate 2001:80:142-7.
28 Wang J, Liang WQ, Wu JJ, et al. Population pharmacokinetic analysis of amikacin and validation on neonates using Monte Carlo method. Acta Pharmacol Sin 2000;21:954-60

29 Langhendries JP, Battisti O, Bertrand JM, et al. Adaptation in neonatology of the once-daily concept of aminoglycoside administration: evaluation of a dosing chart for amikacin in an intensive care unit. Biol Neonate 1998;74:351-62.

30 Botha JH, du Preez MJ, Miller R, et al. Determination of population pharmacokinetic parameters for amikacin in neonates using mixed-effect models. Eur J Clin Pharmacol 1998;53:337-41.

31 Petersen PO, Wells TG, Kearns GL. Amikacin dosing in neonates: evaluation of a dosing chart based on population pharmacokinetic data. Dev Pharmacol Ther 1991:16:203-11.

32 Kenyon CF, Knoppert DC, Lee SK, et al. Amikacin pharmacokinetics and suggested dosage modifications for the preterm infant. Antimicrob Agents Chemother 1990;34:265-8

33 Admiraal R, van Kesteren C, Boelens JJ, et al. Towards evidence-based dosing regimens in children on the basis of population pharmacokinetic pharmacodynamic modelling. Arch Dis Child 2014;99:267-72.

34 Jacqz-Aigrain $\mathrm{E}$, Zhao $\mathrm{W}$, Sharland $\mathrm{M}$, et al. Use of antibacterial agents in the neonate: 50 years of experience with vancomycin administration. Semin Fetal Neonatal Med 2013;18:28-34.

35 Cohen-Wolkowiez M, Ouellet D, Smith PB, et al. Population pharmacokinetics of metronidazole evaluated using scavenged samples from preterm infants. Antimicrob Agents Chemother 2012;56:1828-37.

36 Suyagh M, Collier PS, Millership JS, et al. Metronidazole population pharmacokinetics in preterm neonates using dried blood-spot sampling. Pediatrics 2011;127:e367-374.

37 Pandolfini C1, Kaguelidou F, Sequi $M$, et al. Wide intra- and inter-country variability in drug use and dosage in very-low-birth-weight newborns with severe infections. Eur J Clin Pharmacol 2013;69:1031-6.

38 NICE Clinical Guidence: Antibiotics for early-onset neonatal infection. 2012

39 Porta A, Hsia Y, Doerholt K, et al. Comparing neonatal and paediatric antibiotic prescribing between hospitals: a new algorithm to help international benchmarking. J Antimicrob Chemother 2012;67:1278-86.

40 Neofax. Thomson Reuters Clinical Editorial Staff. 2011.

41 RedBook. American Academy of Pediatrics. 2013.

42 Kaguelidou F, Turner MA, Choonara I, et al. Randomized controlled trials of antibiotics for neonatal infections: a systematic review. Br J Clin Pharmacol 2013:76:21-9.

43 Pansieri C, Bonati M, Choonara I, et al. Neonatal drug trials: impact of EU and US paediatric regulations. Arch Dis Child Fetal Neonatal Ed 2014;99:F438.

44 Benjamin DK Jr, Smith PB, Murphy MD, et al. Peer-reviewed publication of clinical trials completed for pediatric exclusivity. JAMA 2006;296:1266-73.

45 Nicklin S, Spencer SA. Recruitment failure in early neonatal research. Arch Dis Child Fetal Neonatal Ed 2004;89:F281.

46 Amiel P, Moreau D, Vincent-Genod C, et al. Noninvitation of eligible individuals to participate in pediatric studies: a qualitative study. Arch Pediatr Adolesc Med 2007:161:446-50. 